\title{
Glycerol Effect on the Corrosion Resistance and Electrodeposition Conditions in a Zinc Electroplating Process
}

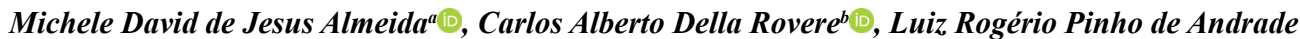 \\ Lima $^{a}{ }^{\circledR}$, Daniel Veras Ribeiro ${ }^{\circledR}$, Carlos Alberto Caldas de Souza ${ }^{a *}$ \\ ${ }^{a}$ Departamento de Ciência e Tecnologia dos Materiais, Universidade Federal da Bahia, \\ Salvador, BA, Brasil \\ ${ }^{b}$ Departamento de Engenharia de Materiais, Universidade Federal da Bahia, Salvador, BA, Brasil
}

Received: July 08, 2018; Revised: January 07, 2019; Accepted: June 24, 2019

\begin{abstract}
Zinc electrodeposition is an economical process of $\mathrm{Zn}$ coating compared to conventional galvanic process. The galvanizing process is used in various industrial sectors to protect ferrous alloys during the corrosion process. In buildings, the galvanizing process is widely used to coat mortar protective screens. The electrodeposition of zinc has a relatively low cost compared to other coating materials for the same purpose; however, its corrosion resistance is lower than that of most protective deposits. This study evaluated the effect of adding glycerol to the electrodeposition bath on the corrosion resistance, deposition efficiency, morphology and microstructure of the zinc electrodeposit in concentrations ranging from 0.03 to $0.82 \mathrm{M}$. The electrodeposition was performed on carbon steel AISI 1020 with a current density of $10 \mathrm{~mA} . \mathrm{cm}^{-2}$. The electroplating solution composition was $0.10 \mathrm{M} \mathrm{ZnCl}_{2}, 2.80 \mathrm{M}$ $\mathrm{KCl}$ and $0.32 \mathrm{M} \mathrm{H}_{3} \mathrm{BO}_{3}$. Electrodeposition time was $17.56 \mathrm{~min}, 5 \mu \mathrm{m}$ thick coating, equivalent to the mass of 7.166E-3 $\mathrm{g}$ of zinc on the steel surface. Evaluation of the corrosion resistance was performed by means of the electrochemical tests of Anodic Voltammetry, Potentiodynamic Polarization and Electrochemical Impedance Spectroscopy (EIS) as well as Weight Loss tests in $\mathrm{NaCl} 0.5 \mathrm{M}$ in 4 (four) different period of immersion. The morphology and microstructures of electrodeposited were analyzed using the techniques of Scanning Electron Microscopy (SEM) and Spectrometry X-Ray Diffraction (XRD). The presence of glycerol in the electrodeposition bath decreased the deposition efficiency; however, it increased corrosion resistance and promoted the formation of more compact and refined electrodeposited coatings. Moreover, the results showed that the corrosion rate does not vary linearly with the addition of glycerol.
\end{abstract}

Keywords: Zinc, glycerol, electrodeposition, corrosion.

\section{Introduction}

The process of zinc electrodeposition is widely used in the corrosion protection of steel, due mainly to its relatively low cost compared to other coatings. The zinc coating obtained from electrodeposition has a good surface finish with good thickness uniformity and furthermore enables good adhesion of paint on its surface ${ }^{1}$. Zinc coatings are used in several applications, such as the coating of steel sheets used in home appliances, the coating of tubes, point-of-sale equipment and fasteners. There are several factors that the properties of zinc coating, such as current densities, temperature, bath $\mathrm{pH}$ and additives.

It has been found ${ }^{2}$ that the gain refinement of zinc deposit is obtained with increasing current density. However there is an optimum current density value for the zinc electrodeposition ${ }^{2,3}$. The increase in current density increases the nucleation rate of the deposit, which results in a higher current efficiency. However, above a certain value the increase in current density causes the deposit deterioration ${ }^{2,4}$. More recently it has been reported that the characteristics of the coating of $\mathrm{Zn}$ obtained by electrodeposition can be improved by the use of pulsed

*e-mail: caldassouza@hotmail.com electrodeposition which raises the corrosion resistance of the coating compared to the direct current used in conventional deposition $^{5-8}$. In a study ${ }^{5}$ on the effect of direct current (DC), pulsed current (PC) and pulsed reverse current (PRC) on structure and corrosion resistance of $\mathrm{Zn}$ coating was found that PC and PCR coatings are more compact, thinner, less porous and more resistant to corrosion compared to DC coatings and these effects are more significant in PCR coatings.

The electrodeposition through PCR allows the obtaining of $\mathrm{Zn}$ coating with nano grained which results in a coating with greater resistance to corrosion and with greater hardness due to high area of grain contours. A higher corrosion resistance for PRC Zn deposits is attributed to formation of compact $\mathrm{ZnO}$ corrosion product on the surface of PRC Zn in contrast to porous zinc hydroxy-chloride on the surface of $\mathrm{DC}$ and $\mathrm{PC} \mathrm{Zn}$ deposits ${ }^{5}$. The presence of the nano grains in the $\mathrm{Zn}$ coatings PCR allows the formation of the $\mathrm{ZnO}$ film because the formation of this film is a controlled diffusion process and the diffusion of the ions to form this film occurs preferentially through the grain boundaries. A high area per unit of the volume of the grain boundaries with nanometric dimension therefore allows the formation of this film, which 
does not occur in the polycrystalline coatings obtained through DC and PC in which the diffusion of the alloying elements is much smaller'.

It is observed ${ }^{10}$ that the temperature rise results in increased current efficiency and lower specific energy consumption. However above a certain temperature this behavior is more observed. Moreover at higher temperatures electrode shortening would become a problem due to nodule formation ${ }^{10}$. The highest current efficiency and lowest specific energy consumption were achieved between $40^{\circ} \mathrm{C}$ and $45^{\circ} \mathrm{C}$ for zinc electrodeposition from acidic sulfate electrolyte ${ }^{10}$. As observed with current density the temperature rise also causes the reduction in the average crystallite size of the zinc deposits ${ }^{2}$. The increase of the current efficiency caused by the increase of the bath deposition temperature can be attributed to a higher rate constant of cathodic reactions and consequently in the lower driving force required to occur the deposition of the zinc ${ }^{10}$.

The effect of $\mathrm{pH}$ on the $\mathrm{Zn}$ electrodeposition process is related to the conductivity of bath deposition and with the hydrogen evolution reaction. As the $\mathrm{pH}$ moves toward lower values, the conductivity of the chemical bath tends to increase ${ }^{10}$. This effect should favor the deposition reactions of the metal ions, thus causing an increase in the current efficiency. However, below a certain $\mathrm{pH}$ the effect of hydrogen evolution becomes predominant and current efficiency decreases ${ }^{10,11}$. With the elevation of the hydrogen ion concentration the rate of hydrogen evolution becomes greater and consequently the fraction of the deposition current to be used in the deposition of the zinc decreases, resulting in the reduction of the current efficiency with the acidification of the bath deposition.

The $\mathrm{pH}$ of bath deposition also affects the quality of the deposit having been verified ${ }^{12}$ a deposit burnt at $\mathrm{pH}$ lower than 2.5 while at $\mathrm{pH} 2.5$ a satisfactory bright deposits were obtained to zinc electrodeposition from sulphate bath content product of glycyl-glycine and furfural. However, the powdery deposit was obtained at $\mathrm{pH}$ of 4 to zinc electrodeposition from acetate solution, while a smooth, uniform, and white deposit was obtained at $\mathrm{pH}$ of $5.0^{13}$. These results indicate that the effect of $\mathrm{pH}$ on the characteristics of the zinc deposit depends on the composition of the deposition bath.

The zinc deposit has a relatively low corrosion resistance in aggressive environments, such as those containing chloride and sulfur oxides. Therefore, it is important to use additives in the electrodeposition bath to improve the corrosion resistance of the coating. It has been reported that several additives ${ }^{14-23}$, affect structure and enhance the corrosion resistance of zinc coatings. Among the additives in the electrodeposition bath that improve the corrosion resistance of zinc coatings are ionic liquids, 1-butyl-3-methylimidazolium hydrogen sulfate $\left(\mathrm{BMIMHSO}_{4}\right)^{14,15}$, polyethyleneglycol $(\mathrm{PEG})^{16,17}$, gelatin $^{18,19}$, urea ${ }^{20}$, polyvinyl alcohol (PVA) + piperol $^{21}$, CTBA (cetyltrimethyl ammonium bromide) $+\mathrm{VV}(\text { veratraldehyde })^{22}$ and coumarin ${ }^{23}$.

The effect of the organic additives on the microstructure of the $\mathrm{Zn}$ deposit is related mainly com the formation of a more compact coating and more refined grains. This behavior is related to the adsorption of additives on the cathode surface during electrodeposition; the additives can retard grain growth and increase the nucleation rate, resulting in finer grain and compacts deposits ${ }^{13-17,24}$.

The organic additives initially preadsorbed on steel sheets successively adsorb onto the deposited $\mathrm{Zn}$ coating as well ${ }^{24}$. The adsorption of additives on the cathode surface during electrodeposition occurs through free electron containing radicals. Among these radicals are oxygen, nitrogen, sulfur and hydrophilic groups (-O-SO $\left.\mathrm{S}_{3} \mathrm{Na}\right)$. Oxygen atoms act as radicals for adsorption in several additives such as urea, gelatin and Polyethylene glycol (PEG). Nitrogen atoms act as radicals for adsorption of stearyl dimethylbenzyl ammonium chloride [SDBAC]. Saccharin is adsorb by oxygen and nitrogen atoms. Hydrophilic groups $\left(-\mathrm{O}-\mathrm{SO}_{3} \mathrm{Na}\right)$ act as radicals for adsorption of sodium lauryl sulfate. $\mathrm{S}$ act as radical for adsorption of thiourea ${ }^{20,24}$.

The intensity with which the organic additive is adsorbed on substrate or zinc deposit depends of electrons number of radicals for adsorption and of molecular weight of additive. A radical for adsorption with more electrons interacts more intensively with the substrate or the zinc deposits ${ }^{20}$. An addive with higher molecular weight tends to have a larger number of radicals for adsorption and therefore a greater adsorption capabiliy. The high adsorption capacity of gelatin is attributed to its high molecular weight ${ }^{24}$. However, when the molecular weight of additive is very high, as occurs in polymers with high molecular weight, the number of effective radicals decreased because of the embroilment of the polymer and the increase of the molecular weight does not favor the additive adsorption. It was found ${ }^{25}$ that when when the molecular weight of polyethylene glycol (PEG) is $<1 \times 10^{4}$, almost all the oxygen radicals are utilized for adsorption to inhibit $\mathrm{Zn}$ deposition effectively. However, when the molecular weight of PEG exceeded $10^{4}$ the number of effective radicals decreased because of the embroilment of the polymer.

The increase of nucleation rate and the retardation of grain growth caused by additives is related with the increase of cathode overpotential and with the inhibition of $\mathrm{Zn}$ deposit growth. The higher cathode overpotential increases the free energy to form new nuclei which results in a higher nucleation rate $^{26}$. It is reported ${ }^{27}$ in chlorite- plate solution that the mixtures of polyacrylamide and thiourea resulta in the high cathode overpotential which decrease the grain size of $\mathrm{Zn}$ coting markedly. A similar effect was also found in sulfateplate solution with the mixture of thiourea and benzalacetone which result in formation of nanocrstalline $\mathrm{Zn}$ deposit $^{28}$. Stearyl dimethylbenzyl ammonium chloride (SDBAC) ${ }^{29}$, 
polyethylene glycol (PEG), gelatin ${ }^{24}$ and coumarin ${ }^{30}$ are other organic additives reported in literature which increase cathodic polarization and cause grain refining. The degree of polarization depends on the number of radicals presents in the additive utilized for adsorption. A smaller number of these radicals may decrease the degree of polarization of the additive ${ }^{15}$.

Generally the organic additives that cause the refining of grains of the $\mathrm{Zn}$ deposit increase of overpotential cathode. However, it is possible that the additive causes grain refining without altering the overpotential cathode. This behavior is found ${ }^{24}$ with the addition of saccharin and also with addition of sodium lauryl sulfate, which causes grain refining without altering the overpotential cathode. It is possible that these additives cause inhibition of the growth of $\mathrm{Zn}$ grains without altering the nucleation rate. Inhibition of the growth of the $\mathrm{Zn}$ deposit grains is related to the absorption of large organic molecules on the cathode which acts as a physical barrier or temporary metal complex formation. This effect results in a low anion surface mobility, which slows grain growth ${ }^{26,31}$. The decrease of grains size also is attributed to the suppression of $\mathrm{Zn}$ normal lateral growth due to the presence of organic additives adsorbed on $\mathrm{Zn}$ growth sites ${ }^{24}$.

The effect of the addition of the organic additives on the corrosion resistance of the $\mathrm{Zn}$ deposit obtained by electrodeposition is related to the composition, texture, morphology, and size of the grains. The presence of close packed crystallographic planes favors the corrosion resistance of the $\mathrm{Zn}$ deposit. These planes has a higher number of nearest neighbouring atoms for binding and thus the total energy required for breaking of bond between the atoms of these planes is higher which favors the elevation of corrosion resistance ${ }^{32}$. The additives that are adsorbed on the electrode can affect the reduction of metal ions and therefore change the crystallographic orientations of the $\mathrm{Zn}$ coating. It was found ${ }^{20}$ that the addition of urea increases the intensity of the (112) plane and this effect has been related to the improvement of the corrosion resistance caused by the presence of this additive. The basal plane (002), whose presence is promoted by the addition of organic additives such as polyvinyl alcohol (PVA), is more compact than the pyramidal (101), (112) and prismatic (110), (100) planes. Therefore, a greater presence of the plane (002) favors the elevation of the corrosion resistance of the $\mathrm{Zn}$ deposit ${ }^{20}$. However, it is important to note that other effects such as a lower surface roughness may prevail over the texture of the plane. This behaviour occurs with the addition of piperone in a bath containing PVA, that although decrease the intensity of the plane (002) can raise the resistance the corrosion of the $\mathrm{Zn}$ deposit $^{20}$.

The effect of the additive on the morphology is a factor of great importance in the corrosion resistance of the $\mathrm{Zn}$ deposit, being observed in several situations that this factor prevails over the effect of the texture of the deposit ${ }^{21}$. A more compact and thus less rough coating caused by the adsorption of organic additive results in a lower corrosion rate. This effect occurs due to less contact occurs between the area of the coating surface and the corrosive medium.

The smaller surface roughness caused by the adsorption of organic additive on the substrate and the deposit of $\mathrm{Zn}$ may be attributed mainly to the finer grain size of the coatings $^{24,31}$. It was found ${ }^{23}$ that the effect of grain refining on the roughness of the $\mathrm{Zn}$ deposit prevails over the crystal orientation effect. Usually the additives that cause the refining of the grains decrease the roughness of the $\mathrm{Zn}$ deposit and make it smooth. This effect is observed with the addition of additives such as gelatin ${ }^{24,33}$ polyethylene glycol (PEG) ${ }^{24,34,25}$, saccharin $^{24}$, tetrabutylammonium chloride (TBACl) ${ }^{25}$, and sodium lauryl sulfate ${ }^{24}$. However, the additive can cause the grain to be refined without reducing the roughness. This behavior was reported ${ }^{24}$ with the addition of ammonium chloride (SDBAC) and is attributed to the formation of a $\mathrm{Zn}$ deposited nonuniformly with the adsorption of this additive.

The effect of grain refining on the corrosion resistance of the $\mathrm{Zn}$ deposit, besides being generally related to the roughness of the deposit, may also be related to the passive film of $\mathrm{ZnO}$. It has been proposed that grain refining increases the number of active nucleation sites of $\mathrm{ZnO}$ on the surface of the coating, which accelerates the formation of this oxide that acts as a passive film, thus favoring the corrosion resistance of the deposit. It is found ${ }^{23}$ that the addition of the organic additives CTAB (cetyltrimethyl ammonium bromide) + VV(veratraldehyde) em um solução alcalina de $\mathrm{NaOH}$, accelerate the formation of $\mathrm{ZnO}$ passive filme o que inhibits the further oxidation of zinc deposits. This effect is attributed to grain refining caused by the addition of these additives, which increases the nucleation rate of $\mathrm{ZnO}$. Grain refining may also favor the formation of the passive film by promoting the diffusional process involved in the formation of this film. It was found ${ }^{35}$ that in a nanocrystalline zinc coatings due to high grain refining, the diffusion of elements materials is much higher than that in polycrystalline materials which favors the formation of the $\mathrm{ZnO}$ film. However, the effect of grain refining on the passive $\mathrm{ZnO}$ film occurs only in a corrosive environmental which this passive film is formed. In $\mathrm{Zn}$ coating obtained by direct current (DC) and pulsed current (PC) the $\mathrm{ZnO}$ passive film is not formed solution acid $^{20,36}$ however, was found ${ }^{36}$, that in $\mathrm{Zn}$ coating obtained by pulsed reverse current (PRC) the passive film can be formed in $\mathrm{NaCl}$ acid solution.

Change in the composition of the $\mathrm{Zn}$ deposit caused by the organic additive may affect the corrosion resistance of the deposit. This effect occurs when the sulfur, which decreases the corrosion resistance of the deposit, is incorporated into the deposits in the presence of additives containing such element. It is found ${ }^{20}$ that adding thiourea results in finer grain size, but does not improve the corrosion resistance of zinc deposits. This behavior is attributed to the incorporation 
of sulphur in the deposit due to the presence of thiourea containing that element.

A prior study ${ }^{37}$ reported that the addition of glycerol to a $\mathrm{Zn}$-Ni plating bath results in a higher corrosion resistance of the coating. In addition, another study ${ }^{38}$ reported that the best zinc coating morphology was obtained with $0.52 \mathrm{M}$ glycerol in the plating bath of the zinc coating electrodeposited onto a platinum substrate.

Oxygen atoms forming a double bond with carbon act often as radicals for adsorption of organic additives in the $\mathrm{Zn}$ deposit, as occurs with urea and coumarin. Oxygen has free electrons that interact with the metallic substrate and with the $\mathrm{Zn}$ deposit being formed, thus allowing the adsorption of additive. In glycerol, as can be seen from Figure 1, that shows its molecular structure, carbon atoms form bonds with hydroxyl groups. The presence of free electrons in the hydroxyl allows the adsorption of glycerol in the $\mathrm{Zn}$ deposit. Therefore, it becomes interesting to analyze the effect of glycerol on the corrosion resistance of the $\mathrm{Zn}$ deposit. It is also important to note that glycerol does not introduce sulfur into the deposit.

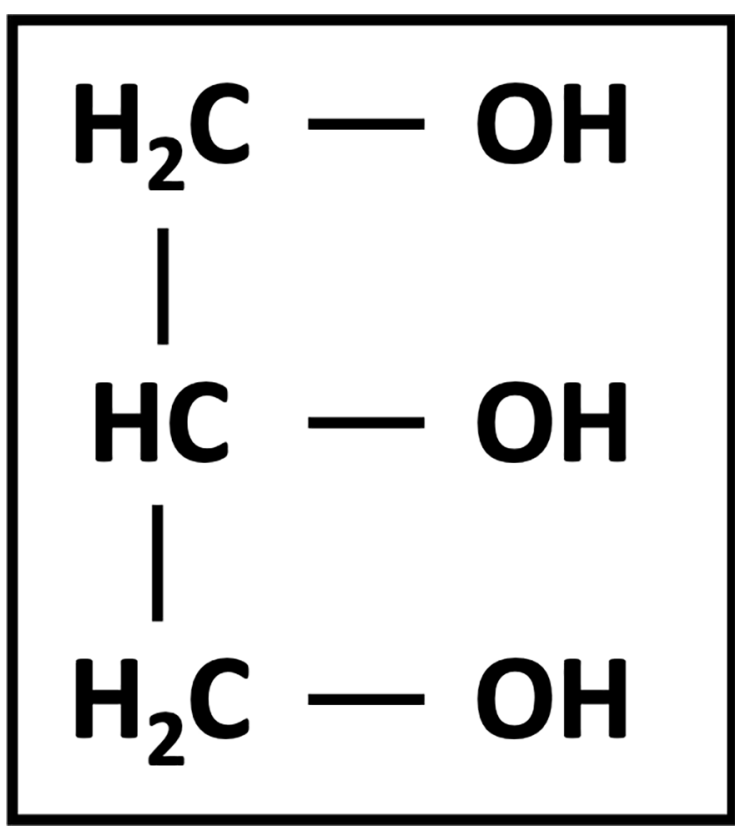

Figure 1. Molecular structure of glycerol.

However, the effect of glycerol on the corrosion resistance of the zinc coating and on the current efficiency deposition of the zinc coating electrodeposited onto a steel substrate was not analyzed. Glycerol is a by-product of biodiesel production that can be obtained by using classical vegetable or animal oil transesterification. Because only a part of the glycerol produced by the transesterification process is commercially utilized, there is a significant excess of this product. Therefore, it becomes interesting to study new applications for glycerol in electrodeposition baths.
The purpose of this paper is to determine how the galvanostatic deposition efficiency and characteristics of the electrodeposited $\mathrm{Zn}$ coating on a steel substrate are affected by the addition of glycerol to the plating bath by analyzing the structure, morphology, and corrosion resistance of the zinc coatings.

\section{Experimental}

The solution composition and conditions for $\mathrm{Zn}$ eletrodeposition are listed in Table 1.

Table 1. Electrodeposition conditions

\begin{tabular}{ccc}
\hline & $\mathrm{ZnCl}_{2}(\mathrm{M})$ & 0.10 \\
Bath Composition & $\mathrm{KCl}(\mathrm{M})$ & 2.80 \\
& $\mathrm{H}_{3} \mathrm{BO}_{3}(\mathrm{M})$ & 0.32 \\
& $\mathrm{pH}$ & 4.8 \\
\hline & $\mathrm{Current} \mathrm{density}$ & 10 \\
Operating & $\left(\mathrm{mA} \cdot \mathrm{cm}^{-2}\right)$ & 25 \\
Conditions & Temperature $\left({ }^{\circ} \mathrm{C}\right)$ & $\mathrm{Fe}\left(1 \times 2 \mathrm{~cm}^{-2}\right)$ \\
& Cathode & Graphite bar \\
& Anode & No stirrer \\
\hline
\end{tabular}

Solutions were prepared from chemicals of analyticalgrade purity dissolved in water purified with a Millipore Milli-Q system. Zinc coatings were electrodeposited onto samples of disc-shaped carbon steel AISI 1020 substrate embedded in crystal resin, with a geometric area of 2.00 $\mathrm{cm}^{2}$ of exposure. Prior to $\mathrm{Zn}$ plating, the carbon-steel surfaces were polished with 200, 400 and 600 SiC emery paper and then cleaned in alcohol and distilled water. The electroplating solution composition was $0.10 \mathrm{M} \mathrm{ZnCl}_{2}, 2.80$ $\mathrm{M} \mathrm{KCl}$ and $0.32 \mathrm{M} \mathrm{H}_{3} \mathrm{BO}_{3}$ and $\mathrm{pH}$ of 4.8 . Six concentrations of glycerol were added to the electrodeposition bath $(0.03$; $0.07 ; 0.14 ; 0.27 ; 0.55$ and $0.82 \mathrm{M}$ ). The parameters used in the galvanostatic deposition were: room temperature; without agitation; current density $10 \mathrm{~mA} . \mathrm{cm}^{-2}$; graphite bar used as anode; electrodeposition time 17 hour and56 min; $5 \mu \mathrm{m}$ thick coating. The electrochemical curves were recorded using an AUTOLAB Potentiostatic\&Galvanostatic model PGSTAT 100 instrument. Coated carbon steel were employed as working electrodes, $\mathrm{Hg} / \mathrm{Hg}_{2} \mathrm{Cl}_{2}$ (saturated calomel electrode - SCE) and graphite were employed as reference and auxiliary, respectively.

The galvanostatic deposition efficiency $(\% E)^{39}$ was evaluated by the ratio between the zinc electroplated mass and the theoretical mass (equation 1):

$$
(\% E)=\left(m_{r} / m_{c}\right) .100
$$

Where: $m_{r}$ is the measured $\mathrm{Zn}$ mass gain, and $\mathrm{m}_{\mathrm{c}}$ is the theoretical mass gain, calculated by equation 2 : 


$$
m_{c}=t_{i} \cdot M_{i} \cdot I / n_{i} \cdot C_{i} \cdot F
$$

Where: $t_{\mathrm{i}}$ is the deposition times (second), $\mathrm{I}$ is the total current passed (amperes), $n_{i}$ is the number of electrons transferred per atom of metal, $\mathrm{C}_{\mathrm{i}}$ is the weight fraction ( 1 to $\mathrm{Zn}$ coating), $\mathrm{M}_{\mathrm{i}}$ is the atomic mass of that element $\left(\mathrm{g} \cdot \mathrm{mol}^{-1}\right), \mathrm{ad} \mathrm{F}$ is the Faraday's constant

Using the Faraday's law the $\mathrm{m}_{\mathrm{c}}$ is related with the thickness of the coating by equation 3 :

$$
t=m_{c} / d z_{n} . S
$$

Were $\mathrm{t}$ is the film thickness, $(5 \mu \mathrm{m}) ; \mathrm{d}_{\mathrm{Zn}}$ is the zinc density, $\left(7.14{\mathrm{~g} . \mathrm{cm}^{-3}}^{-3}\right)$ S is the electrodeposition surface, $\left(2.01 \mathrm{~cm}^{2}\right)$.

Potentiodynamic deposition test consists of a scan of the zinc deposition region (cathode region), followed by scanning of the metal dissolution region (anodic region) at a scan rate of $10 \mathrm{mV} \cdot \mathrm{s}^{-1}$. In the cathodic direction, the initial potential of $-0.8 \mathrm{~V}$ was used, with the potential reverting to anodic direction at $-1.3 \mathrm{~V}$, with the scan ending at the potential of $-0.8 \mathrm{~V}$.

To evaluate corrosion resistance were used methods such as loss of mass in $0.5 \mathrm{M} \mathrm{NaCl}$ solution ( $\mathrm{pH}$ around 6.7), anodic voltammetry and linear polarization at a scan rate $10 \mathrm{mV} . \mathrm{s}^{-1}$ in addition to the Electrochemical Impedance Spectroscopy (EIS) technique. In the mass loss test, the deposits obtained with different glycerol levels in the electrolytic bath and without glycerol addition were immersed during different periods in the corrosive solution $0.5 \mathrm{M} \mathrm{NaCl}(14 \mathrm{~h}, 11 \mathrm{~h}$, $8 \mathrm{~h}$, and $5 \mathrm{~h}$ ). The cleaning of the corrosion product on the surface of the zinc coating after immersion in a corrosive solution was made with solution of glycine (aminoacetic acid $-\mathrm{C}_{2} \mathrm{H}_{5} \mathrm{O}_{2} \mathrm{~N}$ ) $1.36 \mathrm{M}$ at room temperature. The corrosion rate $(\mathrm{CR})$, expressed in $\mathrm{mm}$ per year, was calculated using the following equation (4):

$$
C R=K . W / A . T . D
$$

where $\mathrm{K}=$ constant (for $\mathrm{CR} \mathrm{mm} /$ year, $\mathrm{K}=8.76 \times 10^{4}$ ); $\mathrm{W}$ $=$ mass loss $(\mathrm{g}) ; \mathrm{A}=$ exposed area $\left(\mathrm{cm}^{2}\right) ; \mathrm{T}=$ duration of exposure (h); $\mathrm{D}=$ density (for zinc, $\mathrm{D}=7.14 \mathrm{~g} . \mathrm{cm}^{-3}$ ).

For the EIS plots, the zinc coating was exposed to $0.5 \mathrm{M}$ $\mathrm{NaCl}$ for $3 \mathrm{~min}$ and the reading parameters were as follows: open circuit potential; frequency range $100 \mathrm{KHz}-10 \mathrm{mHz}$ and $10 \mathrm{mV}$ amplitude of the sinusoidal voltage.

The surface morphology at of the electrodeposits were obtained using a JEOL JSM - 6610LV scanning electron microscope (SEM). Roughness of the deposits was analysed by Olympus laser confocal microscope, model LEXT OLS 4100, with 200X objective lenses. A microindenter (Future -Tech Corp. model FM-7E) was used to measures microindentation Vickers film hardness, realized with load of $0.5 \mathrm{~N}$ and time of load of 15 seconds. The coating crystal phase structure was analyzed by X-ray diffraction (XRD) using a SHIMADZU XRD-6000 model instrument equipped with a $\mathrm{Cu}-\mathrm{K} \alpha$ radiation source $(40 \mathrm{kV}$ and $40 \mathrm{~mA})$.
The angular $2 \theta$ range used to identify the peaks was between 10-70 degrees. In addition to the identification of the peaks, compressive stress of the microstructure of electrodeposits was also calculated. The value of microstrain was estimated using the Williamson-Hall method ${ }^{40}$, where the effect of the tension and particle size on half the width and half the peak height are additive.

\section{Results}

\subsection{Zn electrodeposition current efficiency}

The effect of the presence of glycerol in the electrodeposition bath on the current efficiency (CE) of the Zn galvanostatic electrodeposition and on mass of zinc per square meter of the substrate are shown in Figure 2 and in Table 2 respectively. The current efficiency is less than $100 \%$, which indicates that the hydrogen evolution reaction is occurring in parallel with $\mathrm{Zn}$ deposition.

In a previous study ${ }^{37}$, it was determined that the addition of 0.03 and $0.07 \mathrm{M}$ glycerol increases the current efficiency (CE) of Zn-Ni electrodeposit when compared with electrodeposition without glycerol, and the CE decreases with the addition of higher glycerol content. This increase of $\mathrm{CE}$ is attributed to adsorption of glycerol in the surface of the steel substrate, which blocks the active sites of evolution of hydrogen. Therefore, the increase of current efficiency is due to inhibition of hydrogen evolution. For higher levels of glycerol, the strongly adsorbed additive layer covers the cathode surface, which inhibits the zinc deposition.

However, the results in Figure 2 and Table 2 show that the addition of glycerol, including concentrations of 0.03 and $0.07 \mathrm{M}$, decreases the current efficiency of zinc deposition when compared with deposition without glycerol. It is possible that during the $\mathrm{Zn}$ electroplating process, the glycerol uptake was more intense in comparison with the $\mathrm{Zn}-\mathrm{Ni}$ electrodeposition, and the contents of 0.03 to 0.07 $\mathrm{M}$ glycerol was sufficient to form a strongly adsorbed layer that inhibits the zinc electroreduction and consequently reduces the $\mathrm{CE}$.

Table 3 shows that the addition of glycerol in the zinc electrodeposition bath causes a slight decrease in its $\mathrm{pH}$ and conductivity. This parameter is related to a possible increase of the viscosity of the solution and consequently to the decrease in the dispersed capacity of the electrolyte. Therefore, it is possible that this effect contributed to the decrease of EC. This behavior is consistent with the results of galvanostatic deposition, see in Fig. 2.

Figure 3 shows the effect of different glycerol concentrations on the $\mathrm{Zn}$ potentiodynamic electrodeposition. It is observed that the peak in the anodic region, Ia, around $-0.94 \mathrm{~V}$, corresponds to the dissolution of the $\mathrm{Zn}$ and the current density of cathodic peak, Ic, around $-1.19 \mathrm{~V}$, corresponding to electrodeposition of $\mathrm{Zn}$. This curves indicates that the 


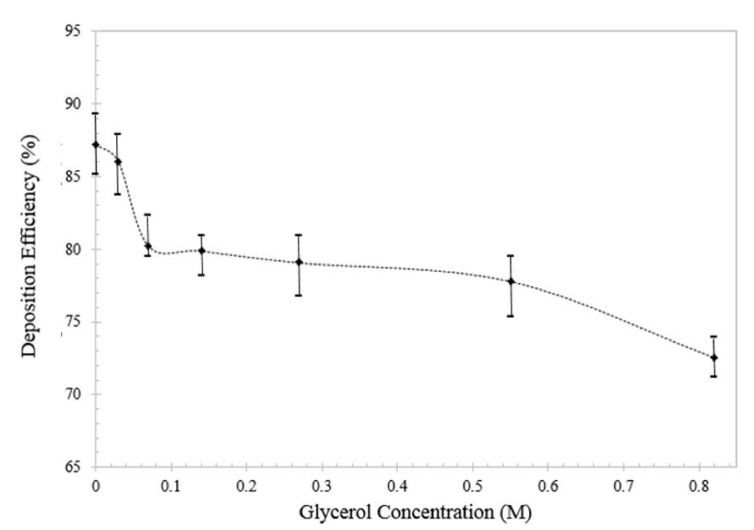

Figure 2. Effect of the presence of glycerol in the deposition bath ( $\mathrm{ZnCl} 0.10 \mathrm{M} ; \mathrm{KCl} 2.8 \mathrm{M} ; \mathrm{H}_{3} \mathrm{BO}_{3} 0.32 \mathrm{M}$ ) on the current efficiency (CE) of the $\mathrm{Zn}$ galvanostatic deposition.

current densit of cathodic peak decrease with the addition of glycerol. However, although this behavior may be consistent with the results of galvanostatic deposition, shown in Fig. 2, it is not possible to state that it indicates the inhibition of the deposition process because the cathodic currents are constantly affected by the variation of the surface area of the electrodeposits.

The voltammogram shown in Figure 3 (see figure insert) corresponds to the potentiodynamic polarization curve obtained with a $\mathrm{Zn}$-free bath and indicates that even in the absence of the $\mathrm{Zn}^{+2}$ cation, a reaction occurs in the cathodic region, suggesting that the hydrogen evolution reaction, represented by: $2 \mathrm{H}^{+}+2^{\mathrm{e}-}\left(\mathrm{H}_{2}\right.$ occurs in parallel with the reduction of zinc, with beginning and end in the same potentials.

\subsection{Evaluation of the physical structure of the $\mathrm{Zn}$ electrodeposits}

Figure 4 shows the diffractograms obtained for samples prepared in the absence and presence of several concentrations of glycerol. As can be seen the diffractograms peaks are formed of thin peaks, as in crystalline structures. The presence of carbon in the electrodeposit can promote the formation of an amorphous structure. The amorphous structure can exhibit a higher corrosion resistance in comparison with the crystalline structure $^{41}$. However, the X-ray diffraction patterns show
Table 3. $\mathrm{pH}$ and Conductivity data of the electrolytic baths

\begin{tabular}{cccc}
\hline Bath & Glycerol M & $\mathrm{pH}$ & $\begin{array}{c}\text { Conductivity } \\
\mathrm{mS} / \mathrm{cm}^{2} 25^{\circ} \mathrm{C}\end{array}$ \\
\hline A & 0 & 4.80 & 179.2 \\
B & 0.03 & 4.77 & 176.6 \\
C & 0.07 & 4.73 & 175.7 \\
D & 0.14 & 4.66 & 173.9 \\
E & 0.27 & 4.56 & 173.3 \\
F & 0.55 & 4.33 & 173.0 \\
G & 0.82 & 4.29 & 171.8 \\
\hline
\end{tabular}

that despite the carbon contained in glycerol, the addition of this additive maintained the crystal structure of the coating.

To determine the effect of glycerol addition on the crystallographic orientation of the electrodeposit, texture co-efficient (RTC, \%) was calculated for each of the peaks of the diffraction pattern. The corresponding $R T C$ values are shown as a bar diagram (Figure 5). It was observed that the RTC values of the basal $\left(\begin{array}{lll}0 & 0 & 2\end{array}\right)$ planes decreased with the addition of glycerol, while the RTC values of the pyramidal (1 0 1) planes tended to decrease with the addition of glycerol. The effect of glycerol on the RTC of prismatic $\left(\begin{array}{lll}1 & 0 & 0\end{array}\right)$ and pyramidal (llll $\left.0 \begin{array}{ll}1 & 0\end{array}\right)$ planes was not obvious.

From the XRD data, the microstrain was also estimated in the compression of $\mathrm{Zn}$ coating in the absence and in the presence of glycerol. The corrosion is favored by the presence of tensile stress on the surface of the metal coating, where it was observed that the increase in corrosion resistance can be related to the compression microstrain ${ }^{42}$. The microstrain values for the compression results are shown in Table 4 and indicate that glycerol did not cause a significant effect on this parameter.

\subsection{Study of morphology and hardness of the $\mathrm{Zn}$ electrodeposits}

Figure 6 shows the physical characterization by SEM of electrodeposited lead films obtained in the absence (Figure 6A, 6C) and the presence (Figure 6B and 6D) of glycerol.

Table 2. Mass of zinc coating per square meter of the substrate $\left(\mathrm{g} / \mathrm{m}^{2}\right)$ obtained from bath deposition containing different concentrations of glycerol.

\begin{tabular}{ccccc}
\hline Bath & Glycerol $(\mathrm{mol} / \mathrm{l})$ & Mass maximum $\left(\mathrm{g} / \mathrm{m}^{2}\right)$ & Mass minimum $\left(\mathrm{g} / \mathrm{m}^{2}\right)$ & Mass average $\left(\mathrm{g} / \mathrm{m}^{2}\right)$ \\
\hline A & 0,0 & 32.02 & 30.52 & 31.27 \\
B & 0.03 & 31.52 & 30.01 & 30.84 \\
C & 0.07 & 29.51 & 28.52 & 29.02 \\
D & 0.14 & 29.02 & 28.02 & 28.64 \\
E & 0.27 & 29.02 & 27.51 & 28.35 \\
F & 0.55 & 28.52 & 27.02 & 27.89 \\
G & 0.82 & 26.51 & 25.51 & 26.01 \\
\hline
\end{tabular}




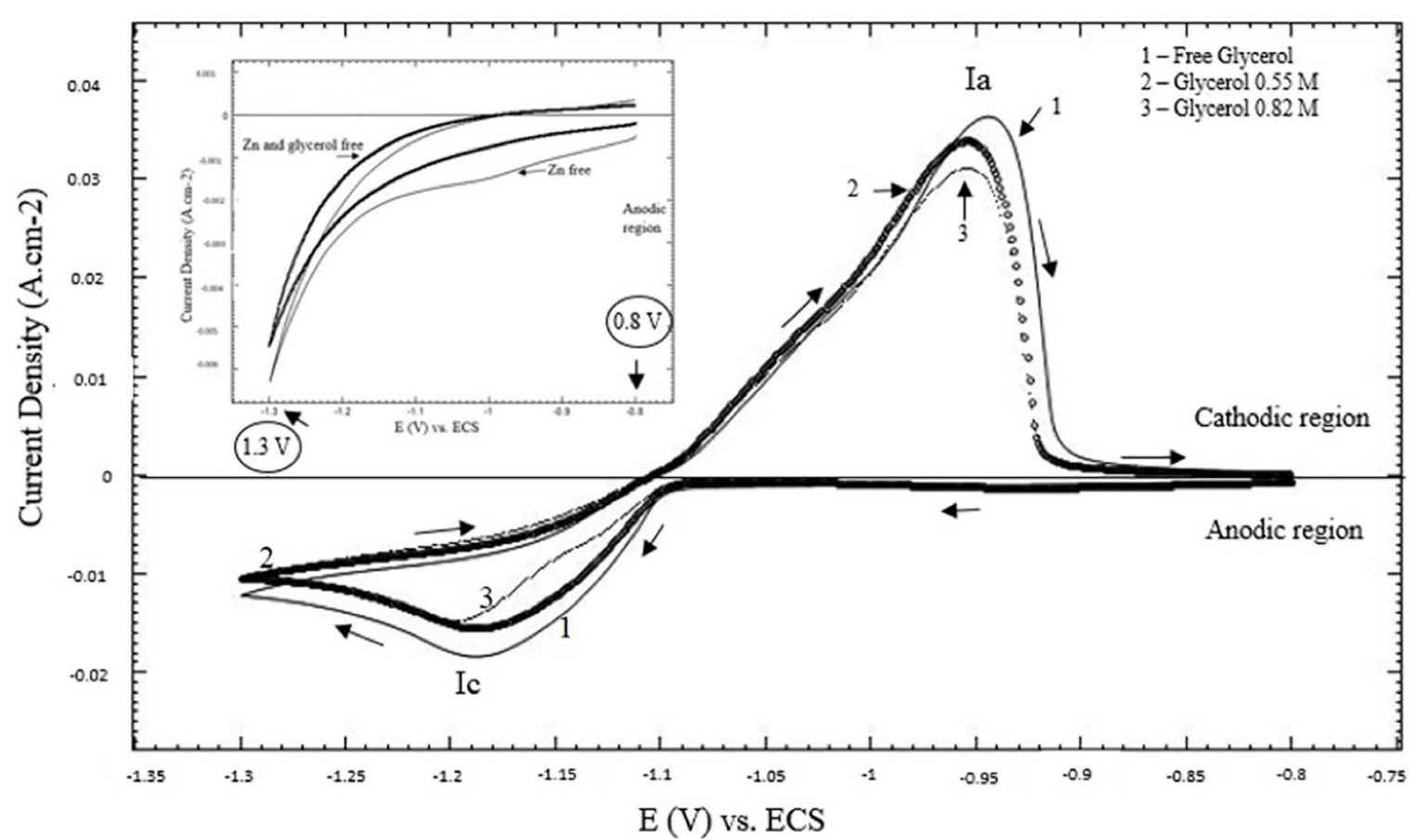

Figure 3. The potentiodynamic polarization curves of 1020 steel substrate immersed in solutions containing different compositions: free, $0.55 \mathrm{M}$ and $0.82 \mathrm{M}$ glycerol
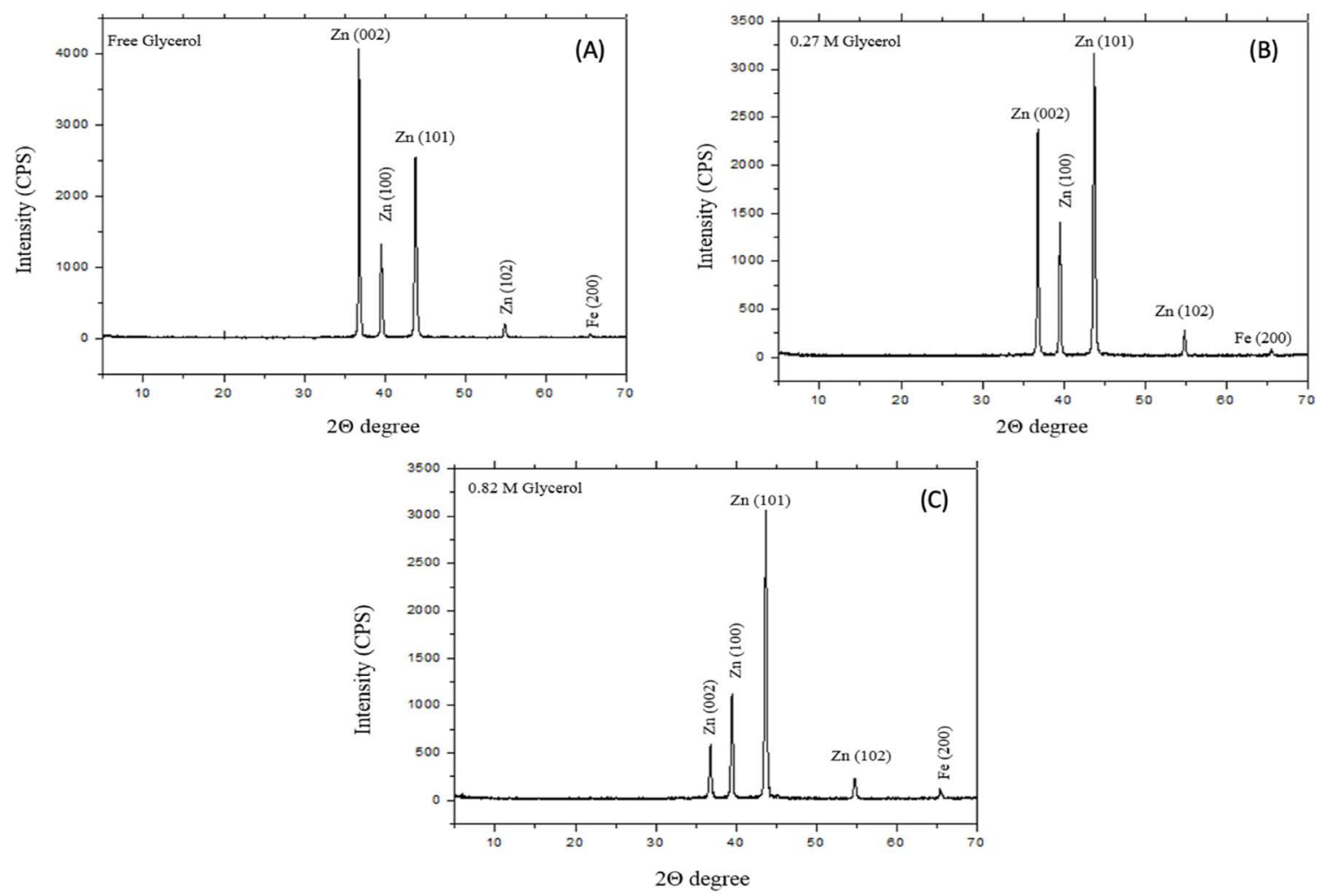

Figure 4. XRD patterns of the coatings obtained (A) without glycerol in the presence of (B) $0.27 \mathrm{M} \mathrm{e}(\mathrm{C}) 0.82 \mathrm{M}$ and in the absence of glycerol 


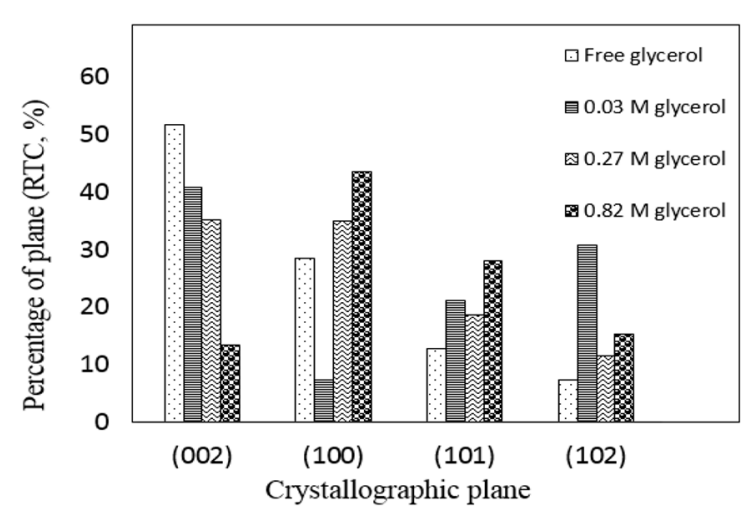

Figure 5. Percentage of $R T C$ as a function of crystallographic planes of zinc coatings obtained in absence and presence of various glycerol contents

Table 4. The microstrain of the compression of $\mathrm{Zn}$ coating in presence and absence of glycerol

\begin{tabular}{ccc}
\hline Bath & Glycerol M & $\begin{array}{c}\text { Compressive } \\
\text { Strain, } \varepsilon\end{array}$ \\
\hline A & 0 & -0.0027 \\
B & 0.03 & -0.0020 \\
C & 0.07 & -0.0025 \\
D & 0.14 & -0.0019 \\
E & 0.27 & -0.0027 \\
F & 0.55 & -0.0022 \\
G & 0.82 & -0.0027 \\
\hline
\end{tabular}
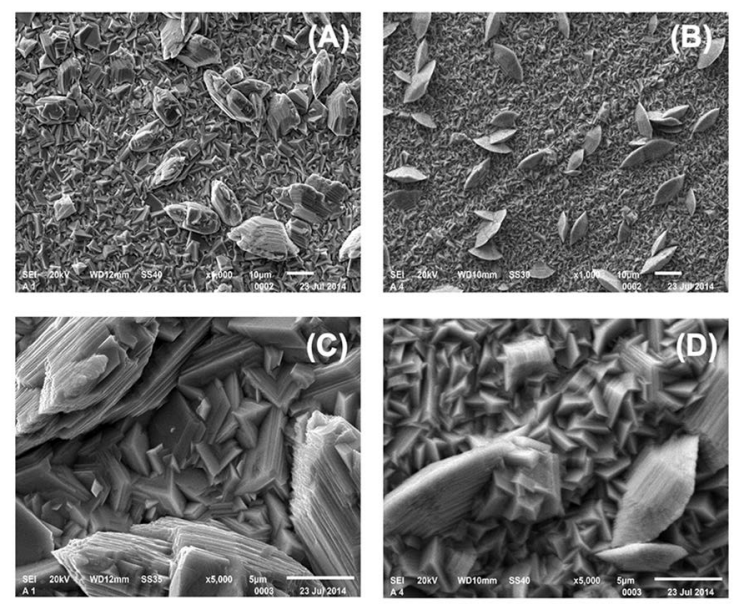

Figure 6. SEM of zinc electroplated steel AISI 1020. (A) micrograph of $\mathrm{Zn}$ coating obtained from a electrodeposition bath containing no glycerol at $1000 \mathrm{X},(\mathrm{B})$ containing $0.82 \mathrm{M}$ glycerol at $1000 \mathrm{X}$, (C) free glycerol at 5000X and (D) containing $0.82 \mathrm{M}$ glycerol at 5000X

The micrographs indicate that glycerol has an effect on the morphology of zinc. It is observed that in the absence of glycerol, larger grains formed that were irregular in size and shape, both on the innermost layer as well as the uppermost layer. Upon the addition of glycerol, grains of more regular size and geometry are formed.
The SEM micrographs in Figure 6 show that the addition of glycerol resulted in a decrease in the grain size and also in the formation of a more compact coating, and this effect increases with increasing glycerol concentration. In order to verify this effect, measurements of hardness and roughness were made in $\mathrm{Zn}$ deposits obtained in the absence and presence of glycerol.

Table 5 shows the Vickers microhardness measurement of $\mathrm{Zn}$ coatings obtained in the absence and the presence of $0.82 \mathrm{M}$ glycerol. The results in this table show that the hardness increases with the presence of the glycerol which indicates that the addition of glycerol promotes the grains refining of $\mathrm{Zn}$ coating.

Table 5. Microhardness values of $\mathrm{Zn}$ coatings

\begin{tabular}{cc}
\hline Specimens & Microhardness / HV 0.05 \\
\hline Zn free glycerol & $51.63 \pm 0.89$ \\
$\mathrm{Zn}+0.82 \mathrm{M}$ glycerol & $60.23 \pm 0.57$ \\
\hline
\end{tabular}

The roughness values of $\mathrm{Zn}$ coatings in the absence and presence of $0.82 \mathrm{M}$ glycerol are listed in Table 6 . These values show that the addition of glycerol decreases the roughness of the $\mathrm{Zn}$ deposit, indicating that the presence of this additive results in a more compact deposit ${ }^{43}$.

Table 6. Roughness values of $\mathrm{Zn}$ coatings

\begin{tabular}{cc}
\hline Specimens & Roughness $/ \mu \mathrm{m}$ \\
\hline $\mathrm{Zn}$ free glycerol & $1.071 \pm 0.229$ \\
$\mathrm{Zn}+0.82 \mathrm{M}$ glycerol & $0.648 \pm 0.080$ \\
\hline
\end{tabular}

This effect of glycerol on the $\mathrm{Zn}$ coating indicates that this addictive is potentially adsorbed on the surface of the cathode during the electrodeposition process, which can increase the nucleation rate and retard grain growth. These two situations combined can result in the refining of the grains. The nucleation rate is the quickness at which the new grains will arise, that is, the higher the rate, the grains are closer together and this limits their growth, which results in the formation of finer and more compact particles, with less area exposed to the corrosive environment ${ }^{14,28}$.

\subsection{Corrosion resistance evaluation}

The effect of glycerol addition to the bath electrodeposition on the corrosion resistance was analyzed using mass loss measurements and electrochemical techniques, which involved obtaining potentiodynamic polarization curves and impedance spectroscopy measurements.

Figure 7 shows the results of mass loss test from corrosion rate data for several immersion period in $\mathrm{NaCl}$ $0.5 \mathrm{M}$ solution. The corrosion rate values indicated that the presence of the glycerol in the electrolytic bath increased the corrosion resistance of $\mathrm{Zn}$ in $0.5 \mathrm{M} \mathrm{NaCl}$. 


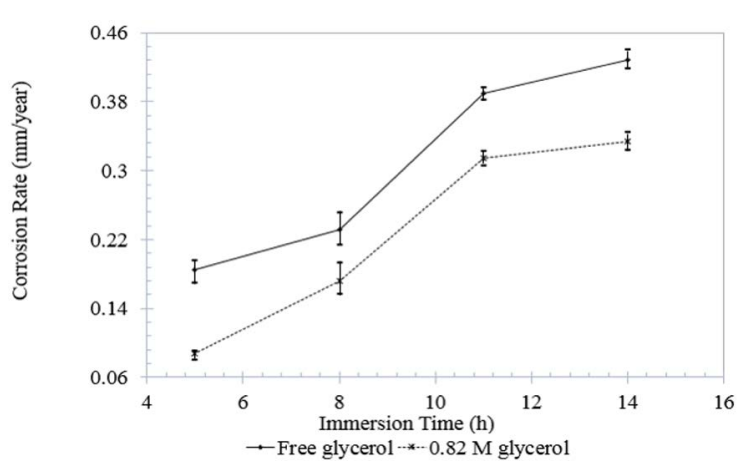

Figure 7. Behavior of the corrosion rate data as a function of immersion period for the concentrations of $0.82 \mathrm{M}$ glycerol and glycerol bath free

According to Figure 7, the corrosion rate is not constantly varying with immersion period. This behavior indicates that the corrosion rate is not limited by an interfacial regime, such as charge transfer ${ }^{44}$. Therefore, in this situation, the evaluation of corrosion resistance based on corrosion current density, icorr, is not appropriate because this parameter is determined from the 'Buttler-Volmer' equation, which is based on conditions in which the corrosion process is controlled only by electron transfer ${ }^{45}$.

To analyze the effect of glycerol addition on the passive film formation behavior on the coating, potentiodynamic polarization curves of electrodeposited $\mathrm{Zn}$ coatings were obtained in the absence and in the presence of glycerol. The curves reported in Figure 8 were obtained using the $2.0 \mathrm{M} \mathrm{NaOH}$ solution. Walking towards the positive potential, the first section (I) is characterized by the sudden increase in current density until the passivation peak is reached. In section II it can be observed that the current density decreases significantly and remains stable over a large range of potential, in this region occurs the formation of the passive film which inhibits the dissolution of $\mathrm{Zn}$. In region III, the passive film formed is ruptured and the current density increases again, this region is also known as transpassivation. The passivation process is characterized by a decrease in the dissolution rate of the metal, which is indicated by a decrease in current density.

The experimental curves showed that this decrease occurred, because, if there was no passivation, the increase in current density would be continuous with the potential, which did not occur. In a prior work ${ }^{46}$ about zinc electrodeposition, the presence of the passive region was also detected in a $2 \mathrm{M}$ $\mathrm{NaOH}$ solution. In this study it was found that the addition of certain concentrations of both sorbitol and $\mathrm{ZnSO} 4$ in the $\mathrm{Zn}$ deposition bath results in a decrease in the current density of the passive region. This behavior indicates, therefore, the presence of the passive film in the coating of $\mathrm{Zn}$. The open circuit potential value in $2 \mathrm{M}$ of $\mathrm{NaOH}$ is $1.043 \mathrm{~V}$ vs. SCE. According to the Pourbaix diagram ${ }^{47}$ at this potential and the $\mathrm{pH}$ of the $2 \mathrm{M}$ solution of $\mathrm{NaOH}$ (14.3) $\mathrm{ZnO}$ is formed on the $\mathrm{Zn}$ surface, which is a compact passive film ${ }^{48}$. However

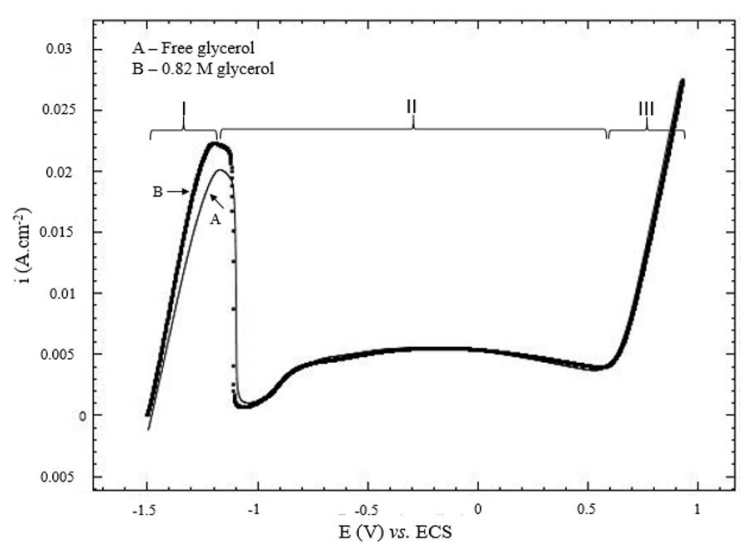

Figure 8. Potentiodynamic polarization curves of the zinc deposits in the absence of glycerol and $0.82 \mathrm{M}$ of glycerol from a $2.00 \mathrm{M}$ $\mathrm{NaOH}$ solution at a scanning speed of $10 \mathrm{mV} \cdot \mathrm{s}^{-1}$

in $0.5 \mathrm{M} \mathrm{NaCl}$ solution the passivation of $\mathrm{Zn}$ does not occur with a continuous increase of the current density in the anodic region. This behavior is observed in Figure 9, which shows the potentiodynamic polarization curve of the $\mathrm{Zn}$ coating in the $0.5 \mathrm{M} \mathrm{NaCl}$ solution.

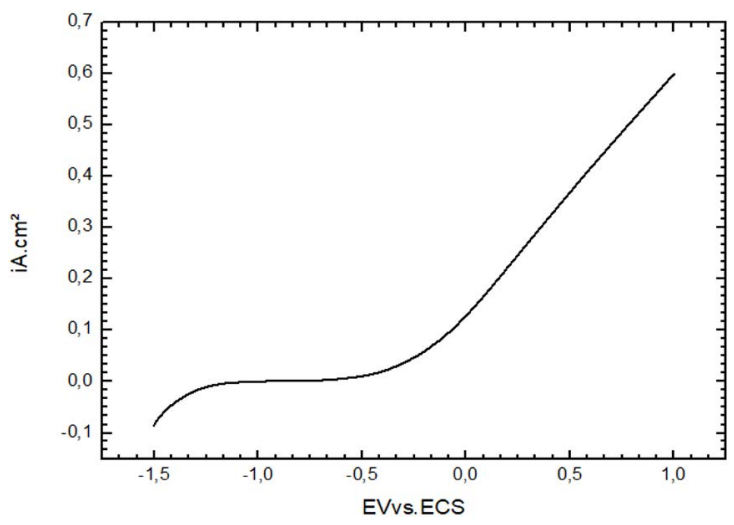

Figure 9. Potentiodynamic polarization curves of the zinc deposits in the absence of glycerol from a $0.5 \mathrm{M} \mathrm{NaCl}$ solution at a scanning speed of $10 \mathrm{mV} \cdot \mathrm{s}^{-1}$

Table 7 shows the effect of glycerol addition on the $\mathrm{ia} / \mathrm{p}$ and $\mathrm{Ea} / \mathrm{p}$. The ia/p is related to the amount of corrosion product required to form the passive film, and $\mathrm{Ea} / \mathrm{p}$ is the potential from which the passive film inhibits the dissolution process. The results in Table 6 indicate that these parameters are not significantly affected by the addition of glycerol in the deposition bath.

The protective performance of passive films is analyzed by current density of the passive region (I) and transpassivation potential, which is the potential at which the current density increase begins after the passive region. A lower current density passive region indicates a larger capacity of the passive film to inhibit the dissolution process, and a higher potential transpassivation indicates a passive film more resistant to breakage. As shown in Figure 8, the addition 
Table 7. Current and potential density data at the peak of active / passive transition

\begin{tabular}{cccc}
\hline Bath & Glycerol M & ia/p A.cm & Ea/p V \\
\hline A & 0 & 0.0200 & -1.18 \\
B & 0.03 & 0.0235 & -1.18 \\
C & 0.07 & 0.0222 & -1.18 \\
D & 0.14 & 0.0220 & -1.14 \\
E & 0.27 & 0.0228 & -1.11 \\
F & 0.55 & 0.0200 & -1.24 \\
G & 0.82 & 0.0220 & -1.18 \\
\hline
\end{tabular}

of glycerol does not have a significant effect on the current density in the passive region or on the transpassivation potential. Therefore, the addition of glycerol does not have an effect on the protective performance of passive films of Zn coatings.

Figure 10 shows the polarization resistance, $\mathrm{Rp}$, obtained from potentiodynamic curves, in $0.5 \mathrm{M} \mathrm{NaCl}$ of $\mathrm{Zn}$ coatings in the absence and presence of various glycerol concentrations. In this solution was not found the passive film formation, which is coherent with the literature ${ }^{20}$.

The Rp values are obtained from the slope of the relationship between the potential and the current density next to corrosion potential in the potentiodynamic curve and are related to the resistance of the electrodeposit to dissolution. Higher Rp values indicate enhanced corrosion resistance. Therefore, the results show that the addition of glycerol decreases the coating dissolution, thus promoting the increase of the coating corrosion resistance.

The effect of the addition of glycerol on the corrosion resistance of the $\mathrm{Zn}$ coating was also studied using electrochemical impedance spectroscopy (EIS). Figure 11 presents Nyquist and Bode curves in $0.5 \mathrm{M} \mathrm{NaCl}$ of the $\mathrm{Zn}$ coating in the absence and presence of glycerol $(0.27 \mathrm{M}$ and $0.82 \mathrm{M})$.

The Nyquist plots, Figure 11 (a) exhibit two semicircles, which are typical spectra of zinc coatings. According to

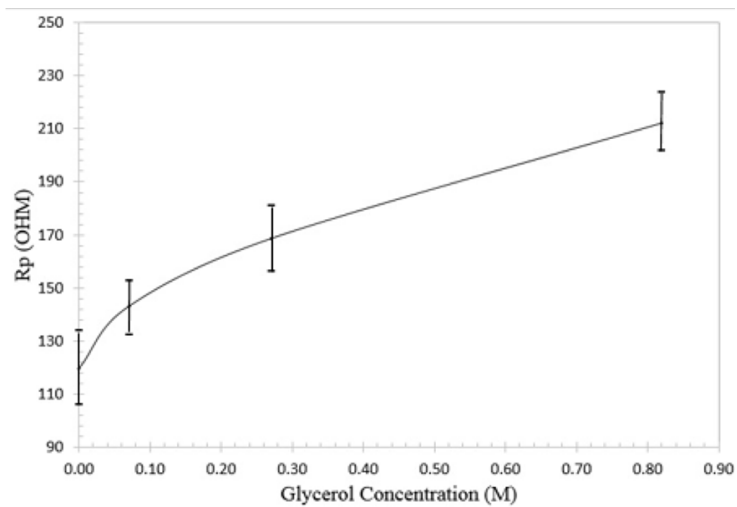

Figure 10. Resistance of polarization, $\mathrm{Rp}$, of $\mathrm{Zn}$ electrodeposited coatings in a $0.5 \mathrm{M} \mathrm{NaCl}$ solution is obtained from deposition baths containing varying amounts of glycerol

the previous studies, ${ }^{49-52}$ the high-frequency loop appears to result from both charge transfer and a film effect of corrosion products. The low-frequency capacitive loop can be attributed to relaxation of mass transport in the solid phase due to the growth of the corrosion product layers (porous $\mathrm{Zn}(\mathrm{OH})_{2} / \mathrm{ZnCl}_{2}$ ) that coat the metallic surface and the intervene in the reduction of oxygen. It can also be observed that the addition of Glycerol increased the diameter of both capacitive loops and, therefore, reduced dissolution rates of the $\mathrm{Zn}$ coatings in the $0.5 \mathrm{M} \mathrm{NaCl}$ solutions.

It should be mentioned that another interpretation of the EIS diagrams is also possible for $\mathrm{Zn}$ coatings: the semicircle at high frequencies can be ascribed to the $\mathrm{Zn}(\mathrm{OH})_{2}, \mathrm{ZnCl}_{2}$ porous layer ${ }^{49,53}$. In Figure $11 b$, the difference between the maximum and minimum values represents the Rp, confirming the previous results of the curve of the coatings obtained in the presence of glycerol exhibiting higher values than those obtained for electrodeposits without this additive.

A qualitative analysis of Nyquist curves shows a larger diameter of the semicircles for the deposit obtained in the presence of glycerol indicates its higher corrosion resistance in the $0.5 \mathrm{M} \mathrm{NaCl}$ solutions, indicating increased corrosion resistance with increasing glycerol concentration.
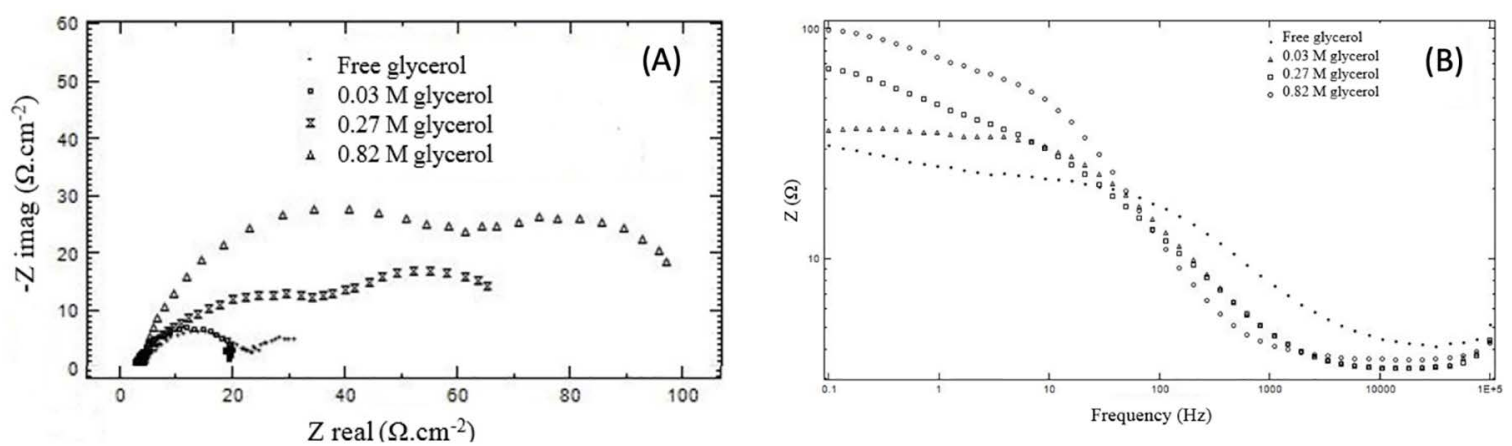

Figure 11. EIS analysis of the $\mathrm{Zn}$ electrodeposit in $0.5 \mathrm{M} \mathrm{NaCl}$, (A) without and (B) in the presence of glycerol. 


\section{Discussion}

The electrochemical impedance results are consistent with the mass loss results and Rp obtained by potentiodynamic polarization curves and show that the addition of glycerol to the bath electrodeposition increases the corrosion resistance of $\mathrm{Zn}$ coating in the $0.5 \mathrm{M} \mathrm{NaCl}$ solution and this effect is larger with increasing glycerol concentration.

The corrosion resistance of $\mathrm{Zn}$ coating in the $0.5 \mathrm{M} \mathrm{NaCl}$ solution is higher for a content of glycerol of $0.82 \mathrm{M}$. The addition of a glycerol concentration above $0.82 \mathrm{M}$ results in a non-adherent electrodeposit on the substrate. However, the addition of $0.82 \mathrm{M}$ glycerol significantly decreases the electrodeposition efficiency (approximately 30\%). In relation to the joint effect in the electrodeposition efficiency and corrosion resistance of the deposit the addition of 0.27 $\mathrm{M}$ glycerol implies in a better behavior, with a decrease of approximately $10 \%$ in the electrodeposition efficiency and a significant increase in the corrosion resistance.

The increase on the corrosion resistance of the $\mathrm{Zn}$ coating with the addition of glycerol in the electrodeposition bath is probably related to the effect of this additive on the morphology and microestrutura of the electrodeposit. As shown in section 3.4, the addition of glycerol promotes formation of a more compact coating with more refined grains. The formation of a more compact electrodeposit implies a smaller contact area between the electrodeposit and the corrosive environment by increasing the corrosion resistance. The increase in glycerol concentration tends to electrodeposit a more compact coating and therefore produces a higher corrosion resistance.

The increase of hardness with the addition of the glycerol reported in Table 5 is probably related to the decrease of the grain size because a coating with highest grain size have a larger density of grain boundaries. Grain boundaries hinder the propagation of dislocations through a material and thus the decrease in grain size raises the hardness of the material. Therefore, the results obtained through the hardness test indicate that the addition of glycerol resulted in a decrease in the grain size which is consistent with SEM micrographs. The increase in hardness of the $\mathrm{Zn}$ deposit with the addition of glycerol indicates that the presence of this additive tends to increase the resistance to wear by abrasion of the deposit, however this behavior will be verified in a future work.

The effect of glycerol on grain refining of the $\mathrm{Zn}$ deposit can be related to the increase in overpotential cathode caused by the addition of this additive. Figure 3 shows shift of potentials (cathodic potentials less negative than the potential corresponding to the current density of cathodic peak, Ic) towards the most negative value at $\mathrm{J}=-10 \mathrm{~mA} \cdot \mathrm{cm}^{-2}$; (current density used to prepare the zinc electrodeposits) with the addition of glycerol. As previously seen, the higher cathode overpotential increases the free energy to form new nuclei which results in a higher nucleation rate, thus favoring grain refining ${ }^{26}$.
In a DC $\mathrm{Zn}$ coating, as the coating analyzed in the present work, in $\mathrm{NaCl}$ solution at $\mathrm{pH}<7$ (acidic media), the corrosion product formed on the coating surface is a porous zinc hydroxy-chloride, which due to its high porosity not acts as passive film ${ }^{34,54}$. Therefore, to analyze the effect of glycerol addition on the passive film formation behavior on the coating were obtained potentiodynamic polarization curves in a $2 \mathrm{M} \mathrm{NaOH}$ alkaline solution, in which the passive $\mathrm{ZnO}$ film formation ${ }^{46}$ occurs.

As seen earlier, the grain refinement accelerates the formation of $\mathrm{ZnO}$ passive film, thus favoring the corrosion resistance of the deposit. However, despite the results obtained by SEM and the hardness test indicated that the addition of glycerol causes grain refining, the results reported in Table 6 and Figure 8 show that the addition of glycerol does not have an effect on the protective performance of passive films of $\mathrm{Zn}$ coatings. It is possible that the refining of grains caused by the addition of glycerol was not sufficient to increase the number of active nucleation sites of $\mathrm{ZnO}$ on the surface of the coating and / or to promote the diffusional process involved in the formation of this film at a sufficient intensity for accelerate the formation of passive $\mathrm{ZnO}$ film. Obtaining $\mathrm{Zn}$ coatings by means of pulse reverse current (PRC), as previously seen (Introduction), makes it possible to obtain coatings with a higher grain refining than those obtained by direct current (DC) and pulse current (PC) makes it possible to obtain a passive film of $\mathrm{ZnO}$ in acid solution of $\mathrm{NaCl}$. In a future study, we will investigate how current density and deposition modes (DC, PC and PRC) influence the effect of glycerol on structural properties and corrosion resistance of $\mathrm{Zn}$ coating.

The increase of the corrosion resistance with the addition of glycerol in the electrodeposition bath contradicts the results reported in Figure 5. These results indicate that the glycerol addition decreases the presence of basal $\left(\begin{array}{lll}0 & 0 & 2\end{array}\right)$ planes, which exhibit a high packing density compared with the other planes present in the electrodeposit. The $\left(\begin{array}{lll}0 & 0 & 2\end{array}\right)$ planes, as observed previously, contribute to increased corrosion resistance, but their presence decreases with the addition of glycerol. This apparent contradiction may be attributed to the fact that the effect of the addition of glycerol in increasing the compactness of the electrodeposit was predominant in relation to the effect of reducing the presence of $\left(\begin{array}{lll}0 & 0 & 2\end{array}\right)$ planes. Similar behavior reported in the literature indicated that the addition of $4.0 \mathrm{M}$ veratraldehyde $(\mathrm{VV})^{22}$ and of 0.4 g. $\mathrm{L}^{-1}$ piperonal in addition to 0.9 g. $\mathrm{L}^{-1}$ polyvinyl alcohol to the $\mathrm{Zn}$ bath deposition ${ }^{21}$ decreases the RTC values of the $(0$ 02 ) planes, although the addition of such additives increases the corrosion resistance of the $\mathrm{Zn}$ coating.

\section{Conclusion}

The presence of glycerol in the electrodeposition bath was found to decrease deposition efficiency, and this effect 
was found to be more intense with increasing glycerol concentration.

The corrosion resistance of the $\mathrm{Zn}$ coating in the 0.5 $\mathrm{M} \mathrm{NaCl}$ solution was found to increase with the glycerol addition in bath electrodeposition, and this effect was found to be more intense with increasing glycerol concentration. The corrosion resistance of the $\mathrm{Zn}$ coating in the $0.5 \mathrm{M} \mathrm{NaCl}$ solution is higher for a glycerol content of $0.82 \mathrm{M}$. The addition of glycerol concentrations greater than $0.82 \mathrm{M}$ was found to result in a non-adherent coating to the substrate.

It was found that the corrosion rate does not change linearly with the glycerol content, which indicates that the corrosion process is not controlled by charge transfer.

The SEM observation, microhardness and roughness measurements indicate that the addition of glycerol in the electrodeposition bath results in grain refinement and more compact $\mathrm{Zn}$ deposits, which promotes the corrosion resistance of the coating.

\section{Acknowledgements}

The authors are grateful to the National Council for Scientific and Technological Development (CNPq) for financial support for completing that work. Special thanks to the teachers of the Department of Science and Technology of Materials and laboratories of the Institute of Chemistry and Nuclear Physics Institute of UFBA by ongoing collaboration in conducting the tests.

\section{References}

1. Parthasaradhy NV. Practical Electroplating Handbook. 1st ed. New Jersey: Prentice-Hall; 1989.

2. Zhang QB, Hua YX, Dong TG, Zhou DG. Effects of temperature and current density on zinc electrodeposition from acidic sulfate electrolyte with [BMIM]HSO4 as aditive. Journal of Applied Electrochemistry. 2009;39:1207-1216.

3. Shivakumara S, Manohar U, Naik YA, Venkatesha TV. Effect of condensation product on electrodeposition of zinc on mild steel. Bulletin of Materials Science. 2007;30(5):463-468.

4. Ebrahimi F, Ahmed Z. The effect of current density on properties of electrodeposited nanocrystalline nickel. Journal of Applied Electrochemistry. 2003;33(8):733-739.

5. Wasekar NP, Jyothirmayi A, Hebalkar N, Sundararajan G. Influence of pulsed current on the aqueous corrosion resistance of electrodeposited zinc. Surface and Coatings Technology. 2015;272:373-379.

6. Youssef KMS, Koch CC, Fedkiw PS. Improved corrosion behavior of nanocrystalline zinc produced by pulse-current electrodeposition. Corrosion Science. 2004;46(1):51-64.

7. Li QY, Feng ZB, Liu LH, Xu H, Ge W, Li FG, et al. Deciphering the formation mechanism of a protective corrosion product layer from electrochemical and natural corrosion behaviors of a nanocrystalline zinc coating. RSC Advances. 2015;5(41):3247932490 .
8. Wang DL, Wu YQ, Zhong XY, Zhang WQ, Li MC, Shen JN. Influence of pulse parameters on nanocrystalline zinc coatings electrodeposited from acidic sulfate electrolyte. Russian Journal of Electrochemistry. 2009;45(3):291-295.

9. R. Wurschum, U. Brossmann, H. Shaefer. Diffusion in nanocrystalline materials. In: Koch CC, ed. Nanostructured Materials: Processing, Properties, and Applications. Noyes Publications, Norwich, New York, 2002, p. 267-299.

10. Scott AC, Pitblado RM, Barton GW, Ault AR. Experimental determination of the factors affecting zinc electrowinning efficiency. Journal of Applied Electrochemistry. 1988;18(1):120127.

11. Pedroza GAG, Souza CAC, de Jesus MD, de Andrade Lima LRP, Ribeiro DV. Influence of formic acid on the microstructure and corrosion resistance of $\mathrm{Zn}-\mathrm{Ni}$ alloy coatings by electrodeposition. Surface and Coatings Technology. 2014;258:232-239.

12. Muralidhara HB, Naik YA, Venkatesha TV. Effect of condensation product of glycyl-glycine and furfural on electrodeposition of zinc from sulphate bath. Bulletin of Materials Science. 2006;29(5):497-503.

13. Krishnan RM, Kennedy CJ, Jayakrishnan S, Sriveeraraghavan S, Natarajan SR, Ramamurthy C, et al. Zinc electrodeposition from acetate solutions. Metal Finishing. 1996;94(10):43-46.

14. Zhang O, Hua Y. Handbook of Surface and Interface Analysis. 2nd ed. Boca Raton: CRC Press; 2009.

15. Sorour N, Zhang W, Ghali E, Houlachi G. A review of organic additives in zinc electrodeposition process (performance and evaluation). Hydrometallurgy. 2017;171:320-332.

16. Morón LE, Méndez A, Castañeda F, Flores JG, Ortiz-Frade L, Meas Y, et al. Electrodeposition and corrosion behavior of $\mathrm{Zn}$ coatings formed using as brighteners arene additives of different structure. Surface and Coatings Technology. 2011;205(2122):4985-4992.

17. Trejo G, Ruiz H, Ortega Borges R, Meas Y. Influence of polyethoxylated additives on zinc electrodeposition from acidic solutions. Journal of Applied Electrochemistry. 2001;31(6):685692.

18. Karahan IH, Çetinkara HA, Güder HS. Electrodeposition and characterization of $\mathrm{Zn}, \mathrm{Zn}-\mathrm{Fe}$ and $\mathrm{Zn}-\mathrm{Fe}-\mathrm{Ni}$ coatings in presence of gelatin as additive. Transactions of IMF. 2008;86(3):157-161.

19. Sekar R, Jayakrishnan S. Characteristics of zinc electrodeposits from acetate solutions. Journal of Applied Electrochemistry. 2006;36(5):591-597.

20. Mouanga M, Ricq L, Douglade J, Berçot P. Effects of some additives on the corrosion behaviour and preferred orientations of zinc obtained by continuous current deposition. Journal of Applied Electrochemistry. 2007;37(2):283-294.

21. Chandrasekar MS, Shanmugasigamani, Pushpavanam M. Synergetic effects of pulse constraints and additives in electrodeposition of nanocrystalline zinc: Corrosion, structural and textural characterization. Materials Chemistry and Physics. 2010;124(1):516-528.

22. Nayana KO, Venkatesha TV. Bright Zinc Electrodeposition and study of influence of synergistic interaction of additives 
on coating properties. Journal of Industrial and Engineering Chemistry. 2010;124(2010):516-528.

23. Mouanga M, Ricq L, Douglade G, Douglade J, Berçot P. Influence of coumarin on zinc electrodeposition. Surface and Coatings Technology. 2006;201(3-4):762-767.

24. Nakano H, Ura T, Oue S, Kobayashi S. Effect of Preadsorption of Organic Additives on the Appearance and Morphology of Electrogalvanized Steel Sheets. ISIJ International. 2014;54(7):16531660 .

25. Ohgai T, Fukushima H, Baba N, Akiyama T. Effect of Polymer Additives on Zinc Electrowinning. In: Dutrizac JE, Gonzalez JA, Henke DM, James SE, Siegmund AHJ, eds. Lead-Zinc 2000. Hoboken: John Wiley \& Sons; 2000.

26. Choo RTC, Toguri JM, El-Sherik AM, Erb U. Mass transfer and electrocrystallization analyses of nanocrystalline nickel production by pulse plating. Journal of Applied Electrochemistry. 1995;25(4):384-403.

27. Youssef KHMS, Koch CC, Fedkiw PS. Influence of Additives and Pulse Electrodeposition Parameters on Production of Nanocrystalline Zinc from Zinc Chloride Electrolytes. Journal of The Electrochemical Society. 2004;151(2):C103-C111.

28. Li MC, Jiang LL, Zhang WQ, Qian YH, Luo SZ, Shen JN. Electrodeposition of nanocrystalline zinc from acidic sulfate solutions containing thiourea and benzalacetone as additives. Journal of Solid State Electrochemistry. 2007;11(4):549-553.

29. MacKinnon DJ, Brannen JM. Evaluation of organic additives as levelling agents for zinc electrowinning from chloride electrolytes. Journal of Applied Electrochemistry. 1982;12(1):21-31.

30. Mouanga M, Ricq L, Ismaili L, Refouvelet B, Berçot P. Behaviour of coumarin in chloride bath: Relationship with coumarin influence on zinc electrodeposition. Surface and Coatings Technology. 2007;201(16-17):7143-7148.

31. Saber K, Koch CC, Fedkiw PS. Pulse current electrodeposition of nanocrystalline zinc. Materials Science and Engineering: A. 2003;341(1-2):174-181.

32. Park H, Szpunar JA. The role of texture and morphology in optimizing the corrosion resistance of zinc-based electrogalvanized coatings. Corrosion Science. 1998;40(4-5):525-545.

33. Kerby RC. Application of Polarization Measurements to the Control of Zinc Electrolyte Quality for Electrowinning. In: Warren IH, ed. Application of Polarization Measurements in the Control of Metal Deposition. Amsterdam: Elsevier Science; 1984.

34. Karavasteva M. The electrodeposition of metal impurities during the zinc electrowinning at high current density in the presence of some surfactants. Hydrometallurgy. 1994;35(3):391-396.

35. Youssef KMS, Koch CC, Fedkiw PS. Improved corrosion behavior of nanocrystalline zinc produced by pulse-current electrodeposition. Corrosion Science. 2004;46(1):51-64.

36. Wasekar NP, Jyothirmayi A, Hebalkar N, Sundararajan G. Influence of pulsed current on the aqueous corrosion resistance of electrodeposited zinc. Surface and Coatings Technology. 2015;272:373-379.

37. Pedroza GAG, de Souza CAC, Carlos IA, de Andrade Lima LRP. Evaluation of the effect of deposition bath glycerol content on zinc-nickel electrodeposits on carbon steel. Surface and Coatings Technology. 2012;206(11-12):2927-2932.

38. de Oliveira EM, Carlos IA. Voltammetric and morphological characterization of zinc electrodeposition from acid electrolytes containing boric-polyalcohol complexes. Journal of Applied Electrochemistry. 2008;389(9):1203-1210.

39. Soares ME, Souza CAC, Kuri SE. Corrosion resistance of a ZnNi electrodeposited alloy obtained with a controlled electrolyte flow and gelatin additive. Surface and Coatings Technology. 2006;201(6):2953-2959.

40. Cullity BD, Stock SR. Elements of X-Ray Diffraction. 3rd ed. New York: Prentice-Hall; 2001.

41. Hasegawa R, ed. Glassy Metals: Magnetic, Chemical and Structural Properties. Boca Raton: CRC Press; 1983.

42. Lehr IL, Saidman SB. Influence of sodium bis(2-ethylhexyl) sulfosuccinate (AOT) on zinc electrodeposition. Applied Surface Science. 2012;258(10):4417-4423.

43. Park CJ, Lohrengel MM, Hamelmann T, Pilaski M, Kwon HS Grain-dependent passivation of surfaces of polycrystalline zinc. Electrochimica Acta. 2002;47(21):3395-3399.

44. Gemelli L. Corrosão de Materiais Metálicos e sua Caracterização Rio de Janeiro: LTC; 2001.

45. Roberge PR. Handbook of Corrosion Engineering. New York: McGraw-Hill; 1999.

46. Pereira MS, Barbosa LL, Souza CAC, de Morais ACM, Carlos IA. The influence of sorbitol on zinc film deposition, zinc dissolution process and morphology of deposits obtained from alkaline bath. Journal of Applied Electrochemistry. 2006;36(6):727-732.

47. Pourbaix M. Atlas of electrochemical equilibria in aqueous solutions. 2nd ed. Houston: NACE; 1974.

48. Cai M, Park SM. Oxidation of Zinc in Alkaline Solutions Studied by Electrochemical Impedance Spectroscopy. Journal of The Electrochemical Society. 1996;143(12):3895-3902.

49. Mouanga M, Ricq L, Douglade J, Berçot P. Corrosion behaviour of zinc deposits obtained under pulse current electrodeposition: Effects of coumarin as additive. Corrosion Science. 2009;51(3):690698.

50. Barranco V, Feliu S Jr., Feliu S. EIS Study of the corrosion behaviour of zinc-based coatings on steel in quiescent $3 \% \mathrm{NaCl}$ solution. Part 1: directly exposed coatings. Corrosion Science. 2004;46(9):2203-2220.

51. Kalinauskas P, Valsiunas I, Samulevicien M, Juzeliunas E. Zinc photo-corrosion in neutral solutions. Corrosion Science. 2001;43(11):2083-2092.

52. Sun H, Liu S, Sun L. A Comparative Study on the Corrosion of Galvanized Steel under Simulated Rust Layer Solution with and without $3.5 \mathrm{wt} \% \mathrm{NaCl}$. International Journal of Electrochemical Science. 2013;8:3494-3509.

53. Winiarski J, Tylus W, Szczygiel B. EIS and XPS investigations on the corrosion mechanism of ternary Zn-Co-Mo alloy coatings in $\mathrm{NaCl}$ solution. Applied Surface Science. 2016;364:455-466.

54. Zhang XG. Corrosion and Electrochemistry of Zinc. New York: Springer US; 1996. 